\title{
Preparation and affinity identification of glutamic acid-urea small molecule analogs in prostate cancer
}

\author{
ZHIWEI ZHANG ${ }^{1}$, ZHENG ZHU $^{2}$, DEYONG YANG ${ }^{1}$, WEIWEI FAN ${ }^{2}$, JIANBO WANG $^{1}$, \\ XIANCHENG $\mathrm{LI}^{1}$, XIAOCHI CHEN ${ }^{1}$, QIFENG WANG ${ }^{1}$ and XISHUANG SONG ${ }^{1}$ \\ ${ }^{1}$ Department of Urology, First Affiliated Hospital of Dalian Medical University, Dalian, Liaoning 116023; \\ ${ }^{2}$ Department of Urology, Dalian Medical University, Dalian, Liaoning 116085, P.R. China
}

Received March 26, 2015; Accepted April 15, 2016

DOI: $10.3892 / 01.2016 .4699$

\begin{abstract}
In recent years, study concerning activity inhibitors of prostate-specific membrane antigen (PSMA) has been concentrated on the glutamic urea (Glu-urea-R) small molecule and its analogs. The present study aimed to synthesize 4 analogs of Glu-urea-R and identify the affinities of these compounds to PSMA. The compounds were synthesized from raw materials, and the experimental procedures of the present study were in accordance with standard techniques under anhydrous and anaerobic conditions. Glu-urea-Lysine (Glu-urea-Lys), Glu-urea-Ornithine (Glu-urea-Orn), Glu-urea-Glutamine (Glu-urea-Gln) and Glu-urea-Asparagine (Glu-urea-Asn) were successfully synthesized, and their structures were confirmed to be as desired using nuclear magnetic resonance spectroscopy and mass spectrometry. An affinity assay was performed to detect the affinity between the various compounds and PSMA expressed from the prostate cancer LNCap cell line. Glu-urea-Gln had the highest affinity to PSMA, followed by Glu-urea-Asn, Glu-urea-Orn and Glu-urea-Lys. In conclusion, the present study demonstrated that Glu-urea-R specifically binds PSMA expressed in the LNCap cell line and inhibits its activity.
\end{abstract}

\section{Introduction}

Prostate cancer (Pca) is the most common malignant tumor in the male genitourinary system, and according to global cancer epidemic statistics, Pca has become the second most common cancer in men, being second only to lung cancer (1). However, there is lack of effective imaging methods for early diagnosis,

Correspondence to: Dr Xishuang Song, Department of Urology, First Affiliated Hospital of Dalian Medical University, 222 Zhongshan Rd, Dalian, Liaoning 116023, P.R. China

E-mail: song-xishuang@163.com

Key words: prostate-specific membrane antigen, Glu-urea-R, prostate cancer, nuclear magnetic resonance spectroscopy, mass spectrometry analysis localized diagnosis of metastases, choice of postoperative treatment and prevention of postoperative recurrence.

Prostate-specific membrane antigen (PSMA) is a newly discovered Pca-associated antigen. It has no or low expression in normal prostate tissues, whereas it is significantly increased in benign prostatic hyperplasia and Pca tissues, particularly in certain Pca cell lines, including the Pca LNCap cell line (2). Therefore, PSMA may become a molecular target for specific diagnosis of Pca. PSMA is a type 2 integrated protein present in the prostate epithelial cell membrane (3), and contains 750 amino acids and has a molecular weight of $100 \mathrm{kDa}$. PSMA has 3 known enzymes with different biological effects (4), as follows: Folyl polyglutamyl- $\gamma$-glutamate carboxypeptidase, also known as folate hydrolase; $N$-acetylated-a-linked acidic dipeptidase (NAALADase); and dipeptidyl peptidase IV.

Cyt-356 is the earliest monoclonal antibody to PSMA, which was developed by Cytogen Corp. (Princeton, NJ, USA), and has been used clinically (5). Cyt-356 binds to PSMA on the cell surface, and may be used for diagnosis and imaging examination of Pca. Heston (6) previously cloned the cDNA of PSMA and produced a series of other antibodies against the outer region of the protein, and Bander et al $(7,8)$ used these antibodies in preclinical and clinical diagnosis and treatment of Pca. In previous years, the implementation of specific small molecules in combination with tumor markers to mediate tumor imaging and surgical positioning has become a novel clinical diagnosis and treatment method for tumors (9). Labeling tumor markers with small molecules has an advantage of rapid serum clearance and good tumor tissue permeability (10). However, small molecular markers have certain limitations in affinity as tumor markers.

In recent years, study on activity inhibitors of PSMA enzymes is concentrated on the glutamic urea small molecule (Glu-urea-R) and its analogs. Glu-urea-R (Fig. 1) is a PSMA (folate hydrolase I) enzyme inhibitor that efficiently and specifically binds to the PSMA on the Pca cell surface, in which Glu-urea is the binding terminal to PSMA and the R-group is the coupling terminal to other chemical groups (8).

Compared with PSMA monoclonal antibodies, Glu-urea-R has the following advantages: Stable biological activity; short half-life in vivo; good permeability to tumor parenchyma and tumor metastases; and low side-effects in vivo $(7,8)$. Kularatne et al (11) coupled Glu-urea-R with 
${ }^{99} \mathrm{mTc}$-Dap-Asp-Cys chelate to obtain a molecular imaging probe that may be used for single-photon emission computed tomography diagnosis of Pca. In addition, Maresca et al (12) designed and synthesized a number of Glu-urea-R molecules that may easily be labeled with radionuclide ${ }^{123}$ iodine and ${ }^{131}$ iodine. Those authors hypothesized that the chemical properties of the R-group and its coupling substrates may significantly impact the affinity of the Glu-urea-R to PSMA. Zhang et al (10) coupled Glu-urea-R and 2,4-dinitrophenol (DNP) to achieve targeted identification of Pca and intended to obtain targeting immunotherapy of Pca by DNP recruiting immune response-associated antibodies (10). These previous studies suggest that Glu-urea-R has a high value in positron emission tomography/computed tomography (PET/CT) diagnosis of Pca. However, there remains a lack of research on positron isotope labeling of Glu-urea-R as a PET/CT probe for Pca.

A previous study has revealed the properties of the R-group in Glu-urea-R, and have demonstrated that the molecular properties of its coupling groups may affect the affinity of a Glu-urea-R molecular probe to PSMA (10). PET/CT molecular imaging probes require radionuclide labeling and ${ }^{18}$ fluroine $\left({ }^{18} \mathrm{~F}\right)$ possesses a relatively long half-life $\left(\mathrm{t}_{1 / 2}=110 \mathrm{~min}\right)$, allowing for an effective and sufficient drug labeling and imaging time. When performing a prosthetic group label of Glu-urea-R using ${ }^{18} \mathrm{~F}$, full consideration to the labeling efficiency and radiochemical purity of the purified products must be provided. In addition, consideration must be given to the affinity of the labeled products to PSMA, the toxicity of ${ }^{18} \mathrm{~F}$-Glu-urea-R to normal cells and the impact of $\mathrm{pH}$ on the affinity of the probe and PSMA. Successful development of a ${ }^{18} \mathrm{~F}$-Glu-urea-R PET/CT probe may provide a novel diagnostic method for Pca. The present study aimed to develop 4 Glu-urea-R small molecular precursor compounds, which is the first step for preparation of a ${ }^{18} \mathrm{~F}$-Glu-urea-R PET/CT molecular probe.

\section{Materials and methods}

\section{Synthesis of Glu-Urea-R}

Background. The reaction was monitored using liquid chromatography-MS (LC-MS) and the synthesized structures of Glu-Urea-R are shown in Fig. 2.

Synthesis of Glu-urea-Ornithine (Glu-urea-Orn). In total, $45 \mathrm{~g} \mathrm{H}-\mathrm{Glu}$ (OBut)-OBut $\mathrm{HCl}$ (Beijing Bomaijie Technology Co., Ltd., Beijing, China) and 2,800 $\mathrm{ml}$ tert-butyl acetate (Beijing Bomaijie Technology Co., Ltd.,) were added to $31.3 \mathrm{~g}$ $\mathrm{HClO}_{4}$ (Shanghai Huayi Group Huayuan Chemical Co., Ltd., Shanghai, China) while stirring for $16 \mathrm{~h}$. $\mathrm{NaOH}$ solution $(5 \mathrm{M}$; $\mathrm{pH}, 7-8$ ) was added and extracted using ethyl acetate (Shanghai Seebio Biotech, Inc., Shanghai, China). Organic facies were dried using sodium sulfate for $30 \mathrm{~min}$. Subsequently, the organic phase was decompressed and distilled to dryness at $35^{\circ} \mathrm{C}$ to obtain the intermediate. A total of $32 \mathrm{~g} \mathrm{H}-\mathrm{Orn}-\mathrm{OBut}$ $\mathrm{HCl}$ and $36 \mathrm{~g}$ triethylamine (Shanghai Seebio Biotech, Inc.) were dissolved in $570 \mathrm{ml}$ dichloromethane (DCM; Shanghai Seebio Biotech, Inc.) under anaerobic conditions $\left(-78^{\circ} \mathrm{C}\right)$. Subsequently, $57 \mathrm{ml}$ DCM solution containing $11 \mathrm{~g}$ triphosgene (Shanghai Seebio Biotech, Inc.) was added to the reaction liquid for $30 \mathrm{~min}$ at $20^{\circ} \mathrm{C}$. The intermediate $(21 \mathrm{~g})$ and $6.6 \mathrm{~g}$ triethylamine were added and stirred for $18 \mathrm{~h}$ at $20^{\circ} \mathrm{C}$. In total, $100 \mathrm{ml}$ DCM was added to the reaction liquid and the organic phase was rinsed with water. The isolated organic phase was dried with sodium sulfate for $30 \mathrm{~min}$. Subsequently, the organic phase was decompressed and distilled to dryness at $35^{\circ} \mathrm{C}$, and the residue underwent column chromatography (DCM: $\mathrm{CH}_{3} \mathrm{OH}$ in a ratio of 50:1) to obtain the crude products. The obtained crude products underwent catalytic hydrogenation for $16 \mathrm{~h}$ by dissolving the crude products in $600 \mathrm{ml}$ carbinol (Shanghai Seebio Biotech, Inc.) with 10\% wetted palladium (9.7 g; Shanghai Seebio Biotech, Inc.). The organic phase was decompressed and distilled to dryness at $35^{\circ} \mathrm{C}$ and the residue underwent column chromatography (DCM: $\mathrm{CH}_{3} \mathrm{OH}$ at a ratio of 50:1) to obtain products (oily).

Synthetic route of Glu-urea-Asparagine (Glu-urea-Asn). In total, $26 \mathrm{~g} \mathrm{H}-\mathrm{Glu}(\mathrm{OBut})-\mathrm{OBut} \mathrm{HCl}$ and $29 \mathrm{~g}$ triethylamine were dissolved in $500 \mathrm{ml}$ DCM under the conditions of nitrogen protection $\left(-78^{\circ} \mathrm{C}\right)$. Subsequently, $50 \mathrm{ml}$ DCM solution containing $8.9 \mathrm{~g}$ triphosgene was added to the reaction liquid for $30 \mathrm{~min}$ at $20^{\circ} \mathrm{C}$. A total of $10 \mathrm{~g} \mathrm{H}-\mathrm{Asn}-\mathrm{OBut} \mathrm{HCl}$ (Sundia MediTech Co., Ltd., Shanghai, China) and $5 \mathrm{~g}$ triethylamine were added and stirred for $18 \mathrm{~h}$ at $20^{\circ} \mathrm{C}$. DCM $(100 \mathrm{ml})$ was added to the reaction liquid and the organic phase was rinsed with water. The isolated organic phase was dried with sodium sulfate for $30 \mathrm{~min}$. Subsequently, the organic phase was decompressed and distilled to dryness at $35^{\circ} \mathrm{C}$ and the residue underwent column chromatography (DCM: $\mathrm{CH}_{3} \mathrm{OH}$ at a ratio of 50:1) to obtain crude products, which were beaten using $n$-heptane (Shanghai Seebio Biotech, Inc.) to obtain the solid substance. The solid was dissolved in $60 \mathrm{ml}$ methanol and slowly added dropwise to $120 \mathrm{ml}$ water, during which the solid was separated out. The mixture was stirred for $1 \mathrm{~h}$ and filtrated, and the filtrate was rinsed and underwent vacuum drying using an oil pump at $40^{\circ} \mathrm{C}$ for $6 \mathrm{~h}$ to obtain the product.

Synthetic route of Glu-urea-Glutamine (Glu-urea-Gln). In total, $21 \mathrm{~g} \mathrm{H}-\mathrm{Glu}(\mathrm{OBut})-\mathrm{OBut} \mathrm{HCl}$ and $23 \mathrm{~g}$ triethylamine were dissolved in $500 \mathrm{ml}$ DCM under the conditions of nitrogen protection $\left(-78^{\circ} \mathrm{C}\right)$. Subsequently, $50 \mathrm{ml}$ DCM solution containing $7.1 \mathrm{~g}$ triphosgene was added to the reaction liquid at $20^{\circ} \mathrm{C}$ for 30 min. H-Gln-OBut $\mathrm{HCl}$ (Sundia MediTech Co., Ltd.) $(10 \mathrm{~g})$ and $4.3 \mathrm{~g}$ triethylamine were added and stirred for $18 \mathrm{~h}$ at $20^{\circ} \mathrm{C}$. Subsequently, $100 \mathrm{ml} \mathrm{DCM}$ was added to the reaction liquid and the organic phase was rinsed with water. The isolated organic phase was dried with sodium sulfate for $30 \mathrm{~min}$, and decompressed and distilled to dryness at $35^{\circ} \mathrm{C}$. The residue underwent column chromatography (DCM: $\mathrm{CH}_{3} \mathrm{OH}$ at a ratio of 50:1) to obtain the crude products, which were beaten using $n$-heptane to obtain the solid substance. The solid was dissolved in $15 \mathrm{ml}$ methanol and slowly added dropwise to $75 \mathrm{ml}$ water, during which the solids were separated out. Subsequently, the mixture was stirred for $1 \mathrm{~h}$ and filtrated, and the filtrate was rinsed and underwent vacuum drying (oil pump) at $40^{\circ} \mathrm{C}$ for $6 \mathrm{~h}$ to obtain the product.

Synthetic route of Glu-urea-Lysine (Glu-urea-Lys). In total, $26 \mathrm{~g} \mathrm{H}-\mathrm{Glu}$ (OBut)-OBut $\mathrm{HCl}$ and $30 \mathrm{~g}$ triethylamine were dissolved in $500 \mathrm{ml}$ DCM under the conditions of nitrogen protection $\left(-78^{\circ} \mathrm{C}\right)$. Subsequently, $50 \mathrm{ml}$ DCM solution containing $9 \mathrm{~g}$ triphosgene was added to the reaction liquid at $20^{\circ} \mathrm{C}$ for 30 min. H-Lys(Z)-OBut $\mathrm{HCl}$ (Sundia MediTech Co., Ltd.) $(20 \mathrm{~g})$ and $5.5 \mathrm{~g}$ triethylamine were added and stirred for 




Figure 1. Structural and functional diagram of glutamic urea small molecule. PMSA, prostate-specific membrane antigen.

$18 \mathrm{~h}$ at $20^{\circ} \mathrm{C}$. In total, $100 \mathrm{ml} \mathrm{DCM}$ was added to the reaction liquid and the organic phase was rinsed with water. The isolated organic phase was dried with sodium sulfate for $30 \mathrm{~min}$ and decompressed and distilled to dryness at $35^{\circ} \mathrm{C}$. The residue underwent column chromatography to obtain the crude products (42 g). The obtained crude products were dissolved in $680 \mathrm{ml}$ methanol and $10 \mathrm{~g} \mathrm{10 \%} \mathrm{wetted} \mathrm{palladium-carbon} \mathrm{(Wako} \mathrm{Pure}$ Chemical Industries, Ltd., Osaka, Japan) was added. The crude products were hydrogenated with $\mathrm{H}_{2}$ and stirred for $16 \mathrm{~h}$ at $18^{\circ} \mathrm{C}$. The organic phase was decompressed and distilled to dryness at $35^{\circ} \mathrm{C}$, and the residue underwent column chromatography (DCM: $\mathrm{CH}_{3} \mathrm{OH}$ at a ratio of 50:1) to obtain products (oily). The products underwent vacuum drying (oil pump) at $40^{\circ} \mathrm{C}$ for $6 \mathrm{~h}$ and were subsequently placed at $-18^{\circ} \mathrm{C}$ for $16 \mathrm{~h}$ to obtain the solid product.

Hydrolysis of Glu-Urea-R molecule. Glu-urea-Orn, Glu-urea-Asn, Glu-urea-Gln, and Glu-urea-Lys were separately added to $10 \mathrm{ml}$ trifluoroacetic acid (Shanghai Seebio Biotech, Inc.), stirred at $20-30^{\circ} \mathrm{C}$ for $2 \mathrm{~h}$, and the reaction liquids were decompressed to dryness to obtain S36886, S36887, S36888 and S36889, respectively.

Affinity experiment of Glu-urea-R small molecule. NAALADase, also known as glutamate carboxypeptidase II, is a metallopeptidase dependent on zinc oxidation that hydrolyzes $N$-acetyl-aspartyl-glutamate (NAAG), resulting in $\mathrm{N}$-acetyl aspartate and glutamate products. PSMA partially hydrolyzes folic acid glutamate to generate glutamate, which is similar to NAAG hydrolysation. PSMA is expressed by LNCap cells (2). Human prostate cancer LNCaP cell lines were obtained from the American Type Culture Collection (Manassas, VA, USA) and maintained in RPMI-1640 medium (Invitrogen; Thermo Fisher Scientific, Inc., Waltham, MA, USA) supplemented with $10 \%$ fetal bovine serum (Gibco; Thermo Fisher Scientific, Inc.) in a humidified incubator at $37^{\circ} \mathrm{C}$ with $5 \% \mathrm{CO}_{2}$. Membrane and cytosolic fractions were obtained from cultured LNCaP cells.

Inhibition constants were determined using a fluorescence-based assay. Briefly, $25 \mu$ l lysates of LNCaP cell extracts were incubated with $12.5 \mu$ l inhibitor (S36886, S36887, $\mathrm{S} 36888$ and S36889) in the presence of $12.5 \mu \mathrm{l} \mathrm{NAAG}(4 \mu \mathrm{M}$;
A



Glu-Urea-Orn

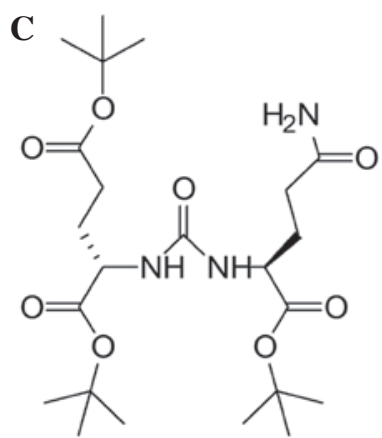

Glu-Urea-Gln
B<smiles>CC(C)(C)OC(=O)CC[C@H](NC(=O)N[C@@H](CC(N)=O)C(=O)OC(C)(C)C)C(=O)OC(C)(C)C</smiles>

Glu-Urea-Asn

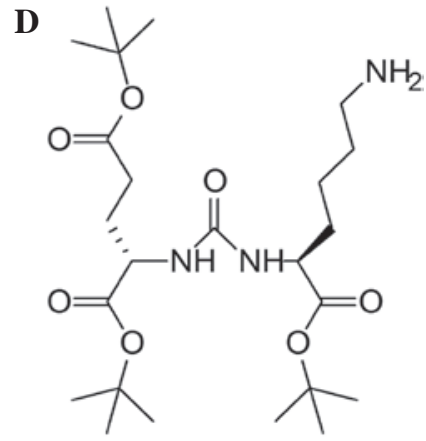

Glu-Urea-Lys

Figure 2. Structures of synthesized Glu-urea small molecules: (A) Glu-urea-Orn, (B) Glu-urea-Asn, (C) Glu-urea-Gln, and (D) Glu-urea-Lys . Glu-urea, glutamic urea small molecule; Orn, Asn, asparagine; Gln, glutamine; Lys, lysine.

\#A5930; Sigma-Aldrich, St. Louis, MO, USA) for $120 \mathrm{~min}$ at $37^{\circ} \mathrm{C}$. NAAG hydrolysis, which is catalyzed by NAALADase, results in the release of $N$-acetyl-aspartate and glutamate. The amount of released glutamate was determined by incubating the cells with $50 \mu \mathrm{l}$ working solution from the Amplex Red Glutamic Acid kit (Invitrogen ${ }^{\mathrm{TM}}$; Thermo Fisher Scientific, Inc.) for $60 \mathrm{~min}$. Fluorescence was measured using an EnSpire Multimode plate reader (PerkinElmer, Waltham, MA, USA) with excitation and emission wavelengths at 490 and $640 \mathrm{~nm}$, respectively. The inhibitor concentration was derived using 2-phosphonomethyl pentanedioic acid (2-PMPA; Santa Cruz Biotechnology, Inc., Dallas, TX, USA), which is a known PSMA inhibitor, as a positive control group and Glu-urea-R was formulated to a suitable concentration by exploring different concentrations of 2-PMPA capable of inhibiting PSMA. Inhibition curves were determined using semi-log plots and half maximal inhibitory concentration $\left(\mathrm{IC}_{50}\right)$ values were calculated.

Statistical analysis. Enzyme inhibitory constants (Ki values) were generated using the Cheng-Prusoff conversion. Data analysis was performed using GraphPad Prism version 4.0 for Windows (GraphPad Software, La Jolla, CA, USA). All experiments were repeated at least three times and the results are expressed as the mean \pm standard deviation. SPSS version 17.0 software (SPSS Inc., Chicago, IL, USA) was used for statistical analysis of the synthesis, hydrolysis and affinity experiments of Glu-urea-R. 
Table I. Inhibition rate of 4 synthetic analogs of Glu-urea-R to prostate-specific membrane antigen.

\begin{tabular}{lcccrr}
\hline & \multicolumn{5}{c}{ Inhibition, $\%$} \\
\cline { 2 - 6 } log concentration, $\mu \mathrm{M}$ & Glu-Urea-Lys & Glu-Urea-Orn & Glu-Urea-Asn & Glu-Urea-Gln & 2-PMPA \\
\hline 1 & 85.488469 & 71.517575 & 87.521311 & 87.316559 & 93.611272 \\
0.3010 & 77.366075 & 81.439916 & 83.885526 & 89.210723 & 92.531223 \\
-0.3979 & 52.428683 & 57.259946 & 65.909721 & 82.020320 & 92.567931 \\
-1.0969 & 8.406071 & 19.438644 & 31.258820 & 58.004315 & 86.281376 \\
-1.7959 & 0.731113 & 7.434516 & 9.939268 & 24.502802 & 61.777146 \\
-2.4949 & -4.746629 & 2.362200 & 1.307847 & 4.772733 & 20.431408 \\
-3.1938 & -4.261259 & 1.230759 & 2.202313 & 1.983285 & 1.781796 \\
-3.8928 & -5.881333 & -3.697986 & 4.722972 & 1.554202 & 0.792702 \\
\hline
\end{tabular}

Glu-urea, glutamic urea small molecule; Orn, Asn, asparagine; Gln, glutamine; Lys, lysine; 2-PMPA, 2-phosphonomethyl pentanedioic acid.

\section{Results}

Synthetic analogs of Glu-Urea-R

Overall. Purities and structural identification of the 4 synthesized compounds were performed using proton nuclear NMR $\left({ }^{1} \mathrm{H}\right.$ NMR) spectroscopy and LC-MS.

Glu-Urea-Orn. Macroscopically, the compound was a white oily substance with a chemical formula of $\mathrm{C}_{23} \mathrm{H}_{43} \mathrm{~N}_{3} \mathrm{O}_{7}$. The purity of the compound was evaluated by high performance liquid chromatography (HPLC) in Sundia MediTech Co., Ltd. The purity of the compound was $97.0 \%$. ${ }^{1} \mathrm{H}$ NMR (400 MHz; $\left.\mathrm{CDCl}_{3}\right)$ : $85.34-5.30(\mathrm{~m}, 2 \mathrm{H}), 4.37-4.30(\mathrm{~m}, 2 \mathrm{H})$, 2.74-2.70 (m, 2H), 2.35-2.27 (m, 2H), 2.08-1.64 (m, 8H), 1.53-1.25 (m, 27H). Electrospray mass spectrometry (ESMS; $\mathrm{m} / \mathrm{z}): 474.3(\mathrm{M}+\mathrm{H})+$.

Glu-Urea-Asn. Macroscopically, the compound was a white solid substance with a chemical formula of $\mathrm{C}_{22} \mathrm{H}_{39} \mathrm{~N}_{3} \mathrm{O}_{8}$. The purity of the compound was $98.6 \% .{ }^{1} \mathrm{H}$ NMR $(400 \mathrm{MHz}$; $\left.\mathrm{CDCl}_{3}\right): \delta 6.42-6.29(\mathrm{~m}, 2 \mathrm{H}), 6.02-5.91(\mathrm{~m}, 2 \mathrm{H}), 4.66-4.61$ $(\mathrm{m}, 1 \mathrm{H}), 4.42-4.36(\mathrm{~m}, 1 \mathrm{H}), 2.94-2.88(\mathrm{~m}, 1 \mathrm{H}), 2.71-2.69(\mathrm{~m}$, $1 \mathrm{H}), 2.34-2.28(\mathrm{~m}, 2 \mathrm{H}), 2.07-2.04(\mathrm{~m}, 1 \mathrm{H}), 1.81-1.70(\mathrm{~m}, 1 \mathrm{H})$, 1.47-1.43 (m, 27H). ESMS (m/z): $474.3(\mathrm{M}+\mathrm{H})+$.

Glu-Urea-Gln. Macroscopically, the compound was a white solid substance with a chemical formula of $\mathrm{C}_{23} \mathrm{H}_{41} \mathrm{~N}_{3} \mathrm{O}_{8}$. The purity of the compound was $97.8 \% .{ }^{1} \mathrm{H}$ NMR $(400 \mathrm{MHz}$; $\left.\mathrm{CDCl}_{3}\right)$ : $\delta 6.83(\mathrm{~m}, 1 \mathrm{H})$, 5.76-5.58 (m, 2H), 4.37-4.30 (m, 2H), 2.35-2.05 (m, 2H), 1.89-1.80 (m, 2H), 1.47-1.43 (m, 27H). $\operatorname{ESMS}(\mathrm{m} / \mathrm{z}): 488.3(\mathrm{M}+\mathrm{H})+$.

Glu-Urea-Lys. Macroscopically, the compound was a white oily substance with a chemical formula of $\mathrm{C}_{24} \mathrm{H}_{45} \mathrm{~N}_{3} \mathrm{O}_{7}$. The purity of the compound was $97.5 \%$. ${ }^{1} \mathrm{H}$ NMR $(400 \mathrm{MHz}$; $\left.\mathrm{CDCl}_{3}\right): \delta 5.34-5.30(\mathrm{~m}, 2 \mathrm{H}), 4.36-4.31(\mathrm{~m}, 2 \mathrm{H}), 2.72-2.68$ (m, 2H), 2.35-2.28 (m, 2H), 2.08-2.06 (m, 1H), 1.93-1.84 (m, $2 \mathrm{H}), 1.77-1.76(\mathrm{~m}, 2 \mathrm{H}), 1.63-1.61(\mathrm{~m}, 1 \mathrm{H}), 1.50-1.34(\mathrm{~m}, 31 \mathrm{H})$. $\operatorname{ESMS}(\mathrm{m} / \mathrm{z}): 488.4(\mathrm{M}+\mathrm{H})+$.

\section{Glu-Urea-R treatment}

Overall. Prior to the affinity experiment, tert-butyl in Glu-urea-R was hydrolyzed to expose the active carboxyl group, so that the compound would bind to PSMA.
Table II. $\mathrm{IC}_{50}$ value of synthetic analogs of Glu-urea-R.

\begin{tabular}{lc}
\hline Compound & $\mathrm{IC}_{50}, \mu \mathrm{M}$ \\
\hline Glu-Urea-Lys & 0.381 \\
Glu-Urea-Orn & 0.271 \\
Glu-Urea-Asn & 0.184 \\
Glu-Urea-Gln & 0.054 \\
2-PMPA & 0.010
\end{tabular}

$\mathrm{IC}_{50}$, half maximal inhibitory concentration.

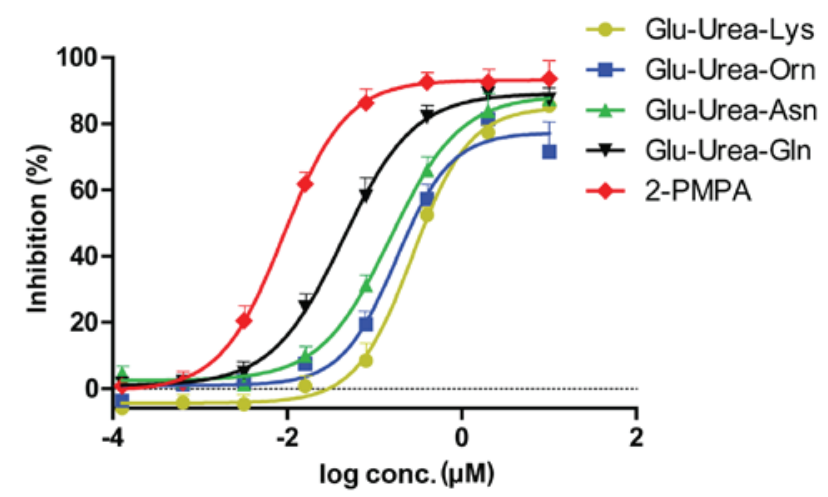

Figure 3. Inhibition curves of 4 synthesized Glu-urea-R analogs against prostate-specific membrane antigen. Glu-urea, glutamic urea small molecule; Orn, Asn, asparagine; Gln, glutamine; Lys, lysine; 2-PMPA, 2-phosphonomethyl pentanedioic acid.

Hydrolytic products of Glu-Urea-Orn (S36886). The chemical formula is $\mathrm{C}_{13} \mathrm{H}_{20} \mathrm{~N}_{3} \mathrm{~F}_{3} \mathrm{O}_{9} \cdot{ }^{1} \mathrm{H}$ NMR (400 MHz): deuterated water $\left(\mathrm{D}_{2} \mathrm{O}\right), \delta 4.213-4.189(\mathrm{~m}, 1 \mathrm{H}), \delta 4.062-4.035$ $(\mathrm{m}, 1 \mathrm{H}), \delta 3.219-3.211(\mathrm{~d}, 2 \mathrm{H}), \delta 2.458-2.423(\mathrm{~m}, 2 \mathrm{H})$,


$(\mathrm{m}, 4 \mathrm{H}) . \operatorname{ESMS}(\mathrm{m} / \mathrm{z}): 304(\mathrm{M}-\mathrm{H})$.

Glu-urea-Asn (S36887). The chemical formula is $\mathrm{C}_{10} \mathrm{H}_{15} \mathrm{~N}_{3} \mathrm{O}_{8} .{ }^{1} \mathrm{H}$ NMR (400 MHz): $\mathrm{D}_{2} \mathrm{O}, \delta 4.680-4.488(\mathrm{~m}, 1 \mathrm{H})$,

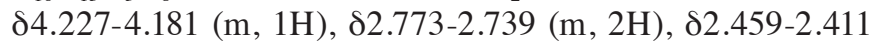


(m, 2H), $82.137-2.073(\mathrm{~m}, 1 \mathrm{H}), \delta 1.929-1.881$ (m, 1H). ESMS (m/z): $304(\mathrm{M}-\mathrm{H})$.

Glu-urea-Gln (S36888). The chemical formula is $\mathrm{C}_{11} \mathrm{H}_{17} \mathrm{~N}_{3} \mathrm{O}_{8} .{ }^{1} \mathrm{H}$ NMR (400 MHz): $\mathrm{D}_{2} \mathrm{O}, 84.193-4.152(\mathrm{~m}, 2 \mathrm{H})$,

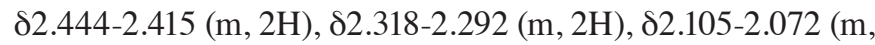
$2 \mathrm{H}), \delta 1.906-1.882$ (m, 2H). ESMS (m/z): 318 (M - H).

Glu-urea-Lys (S36889). The chemical formula is $\mathrm{C}_{14} \mathrm{H}_{22} \mathrm{~N}_{3} \mathrm{~F}_{3} \mathrm{O}_{9} .{ }^{1} \mathrm{H} N M R(400 \mathrm{MHz})$ : $\mathrm{D}_{2} \mathrm{O}, \delta 4.211-4.129(\mathrm{~m}, 2 \mathrm{H})$,

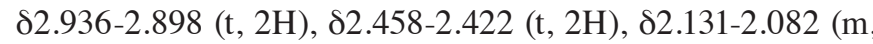

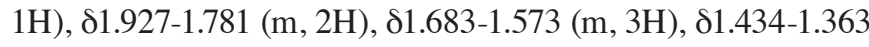
(m, 2H). ESMS (m/z): $304(\mathrm{M}-\mathrm{H})$.

Affinity assays of Glu-Urea-R. Glu-urea-R of various concentrations were added to the lysates of $\mathrm{LNCaP}$ cells, and fluorescence assays were performed. The 2-PMPA group was considered to be the complete inhibition group (positive control) and Tris was used as the negative control. Therefore, the absorbance was obtained by subtracting the absorbance of each compound from the absorbance of the Tris group. The inhibition rate was calculated as follows: Inhibition rate $=1-[(\operatorname{Avg} \mathrm{X}) \mathrm{x}$ (Tris) $] /[$ (Avg PSMA) (Avg Tris)], where $X$ denotes a generic compound. The inhibition rate of each group are shown in Table I. The inhibition curves and $\mathrm{IC}_{50}$ value of the 4 compounds obtained are revealed in Fig. 3 and Table II, respectively. The compound with the highest affinity to PSMA was Glu-urea-Gln, followed by Glu-urea-Asn, Glu-urea-Orn and Glu-urea-Lys.

\section{Discussion}

Individualized diagnosis is the main objective for early Pca diagnosis, and it aims to achieve detection of Pca in advanced stages, prevent local development and metastasis of Pca, reduce Pca mortality and improve the quality of life of patients. A study that took place in Tyrol in Austria revealed that early screening and diagnosis may reduce the Pca mortality rate by $33 \%$ (13). Another study in Canada demonstrated that a lower mortality rate may be achieved in individuals that actively cooperate with Pca examination (14). A study by the European Randomized Study of Screening for Prostate Cancer and the Prostate, Lung, Colorectal, and Ovarian cancer screening trial found that performing the prostate-specific antigen (PSA) test for Pca once every 4 year reduces the mortality of Pca by $20 \%$ (15). However, there are risks of overdiagnosis using this method (15), and consequently, it is inappropriate to perform large-scale screenings of Pca, but it remains necessary to educate individuals about early examination. Although conventional imaging methods have achieved considerable progress in sensitivity and accuracy, there is a lack of effective imaging measures for early diagnosis, localized diagnosis of metastases, choice of postoperative treatment and prevention of postoperative recurrence, and it is challenging to obtain a clear diagnosis of early Pca $(16,17)$.

A digital rectal examination combined with a PSA assay is widely recognized as the best screening method for early Pca (18). With the development of novel technologies, novel diagnostic methods have gradually been identified. PCA3 is a novel biological marker that is detected in the urine sediment, and it is one of the most specific markers of Pca (19). Another diagnostic method is gene detection; genome-wide association studies revealed that at present $>30$ susceptible loci are associated with Pca in various populations around the world (19). Furthermore, it was demonstrated that an increase in hypermorph susceptibility genes of Pca leads to an increased risk for Pca, which meant that Pca susceptibility genes have a clear cumulative effect (20).

$\mathrm{PET} / \mathrm{CT}$ is a diagnostic imaging technique that combines cellular molecular metabolism with morphology (21). Radionuclide-labeled tracer or molecular probes targeting tumor cells effectively identify tumor lesions that are challenging to detect with traditional imaging methods, and $\mathrm{PET} / \mathrm{CT}$ has become a powerful tool for the clinical diagnosis of tumors (22). At present, ${ }^{11} \mathrm{C}$-choline and other cell metabolic substrates are used as PET/CT tracers, which have achieved a certain efficacy in the diagnosis of Pca $(23,24)$. However, these tracers lack specificity to Pca, and it is challenging to distinguish between primary and metastatic Pca, which is prone to false-positive results of benign prostatic hyperplasia and prostatitis lesions $(23,24)$. Therefore, it is essential to identify an efficient and specific molecular probe to improve the sensitivity and accuracy of PET/CT in the diagnosis of Pca, which may be capable of effectively providing early diagnosis, preoperative staging, postoperative recurrence and restaging and postoperative efficacy evaluation and detection.

PSMA as a target protein has become a major study topic in recent years. Glu-urea-R inhibits the activity of PMSA, and effectively and specifically binds to PSMA on the Pca cell surface. Compared with the PSMA monoclonal antibody, Glu-urea-R is characterized by stable biological activity, short in vivo half-life, good permeability to tumor parenchyma and tumor metastases and low side-effects in vivo (8). At present, studies have demonstrated that Glu-urea-R PET/CT molecular probes may provide novel means for the diagnosis of Pca (12).

The present study investigated the preparation of Glu-urea-R analogs that target PSMA. Raw materials were employed to obtain the desired compounds under anhydrous conditions, nitrogen protection and a controlled reaction temperature. NMR spectroscopy and LC-MS confirmed that the obtained products had the desired structures, and their purities were identified to be $>97 \%$ using HPLC. Previous studies have confirmed that Glu-urea-R, which contains a free carboxyl group III in its R-group, can bind with high affinity to the active site of PSMA (11). Therefore, Glu-urea-R analogs are capable of binding to PSMA. Glu-urea is the part of the molecule that binds to PSMA, and the R-group is easily connected to other chemical groups. Affinity experiments of the 4 compounds synthesized by the present study, Glu-urea-Gln ,Glu-urea-Lys, Glu-urea-Asn and Glu-urea-Orn, to PSMA were performed to preliminarily determine their binding activity with Pca cells and compare their affinities, so as to provide data for future experiments.

Overall, the present study revealed that these analogs, particularly Glu-urea-Asn, provided an enriched choice for positron isotope labeling, since they had a high affinity to PSMA. Positron isotopes are used to label Glu-urea-R to investigate Pca using PET/CT, and these compounds have high specificity and sensitivity and low toxicity, therefore providing novel strategies for early diagnosis, preoperative staging, postoperative recurrence and restaging, targeted therapy of 
Pca as well as patient selection for targeted therapy, efficacy evaluation and monitoring. In conclusion, the present study demonstrated that Glu-urea-R specifically binds to PSMA expressed in prostate cell line LNCap and inhibits its activity, which is important for the provision of novel diagnostic methods for Pca.

\section{Acknowledgements}

The present study was supported by the National Natural Science Foundation of China (Beijing, China; grant nos., 30670544 and 81271603). The authors would like to thank Sundia MediTech Company, Ltd. (Shanghai, China) for performing the synthesis of and hydrolysis of Glu-urea-R and providing excellent technical support.

\section{References}

1. Ferlay J, Shin HR, Bray F, Forman D, Mathers C and Parkin DM: Estimates of worldwide burden of cancer in 2008: GLOBOCAN 2008. Int J Cancer 127: 2893-2917, 2010.

2. Risk MC, Knudsen BS, Coleman I, Dumpit RF, Kristal AR, LeMeur N, Gentleman RC, True LD, Nelson PS and Lin DW: Differential gene expression in benign prostate epithelium of men with and without prostate cancer: Evidence for a prostate cancer field effect. Clin Cancer Res 16: 5414-5423, 2010.

3. Wang W and Mo ZN: Advances in prostate-specific membrane antigen targeted therapies for prostate cancer. Zhonghua Nan $\mathrm{Ke}$ Xue 16: 547-551, 2010 (In Chinese).

4. Cheng L, Song SY, Pretlow TG, Abdul-Karim FW, Kung HJ, Dawson DV, Park WS, Moon YW, Tsai ML, Linehan WM et al: Evidence of independent origin of multiple tumors from patients with prostate cancer. J Natl Cancer Inst 90: 233-237, 1998.

5. Li J, Zhao X, Chen L, Guo H, Lv F, Jia K, Yv K, Wang F, Li C, Qian J, et al: Safety and pharmacokinetics of novel selective vascular endothelial growth factor receptor-2 inhibitor YN968D1 in patients with advanced malignancies. BMC Cancer 10: 529, 2010.

6. Heston WD: Significance of prostate-specific membrane antigen (PSMA). A neurocarboxypeptidase and membrane folate hydrolase. Urologe A 35: 400-407, 1996 (In German).

7. Bander NH, Nanus DM, Milowsky MI, Kostakoglu L, Vallabahajosula S and Goldsmith SJ: Targeted systemic therapy of prostate cancer with a monoclonal antibody to prostate-specific membrane antigen. Semin Oncol 30: 667-676, 2003

8. Bander NH, Trabulsi EJ, Kostakoglu L, Yao D, Vallabhajosula S, Smith-Jones P, Joyce MA, Milowsky M, Nanus DM and Goldsmith SJ: Targeting metastatic prostate cancer with radiolabeled monoclonal antibody J591 to the extracellular domain of prostate specific membrane antigen. J Urol 170: 1717-1721, 2003.

9. Elsässer-Beile U, Reischl G, Wiehr S, Bühler P, Wolf P, Alt K, Shively J, Judenhofer MS, Machulla HJ and Pichler BJ: PET imaging of prostate cancer xenografts with a highly specific antibody against the prostate-specific membrane antigen. J Nucl Med 50: 606-611, 2009.

10. Zhang AX, Murelli RP, Barinka C, Michel J, Cocleaza A, Jorgensen WL, Lubkowski J and Spiegel DA: A remote arene-binding site on prostate specific membrane antigen revealed by antibody-recruiting small molecules. J Am Chem Soc 132: 12711-12716. 2010
11. Kularatne SA, Wang K, Santhapuram HK and Low PS: Prostate-specific membrane antigen targeted imaging and therapy of prostate cancer using a PSMA inhibitor as a homing ligand. Mol Pharm 6: 780-789, 2009.

12. Maresca KP, Hillier SM, Femia FJ, Keith D, Barone C, Joyal JL, Zimmerman CN, Kozikowski AP, Barrett JA, Eckelman WC and Babich JW: A series of halogenated heterodimeric inhibitors of prostate specific membrane antigen (Psma) as radiolabeled probes for targeting prostate cancer. J Med Chem 52: 347-357, 2009.

13. Bartsch G, Horninger W, Klocker H, Reissigl A, Oberaigner W, Schönitzer D, Severi G, Robertson C and Boyle P; Tyrol Prostate Cancer Screening Group: Prostate cancer mortality after introduction of prostate-specific antigen mass screening in the federal state of tyrol, Austria. Urology 58: 417-424, 2001.

14. Labrie F, Candas B, Dupont A, Cusan L, Gomez JL, Suburu RE, Diamond P, Lévesque J and Belanger A: Screening decreases prostate cancer death: First analysis of the 1988 Quebec prospective randomized controlled trial. Prostate 38: 83-91, 1999.

15. Schroder FH, Hugosson J, Roobol MJ, Tammela TL, Ciatto S, Nelen V, Kwiatkowski M, Lujan M, Lilja H, Zappa M, et al: Screening and prostate-cancer mortality in a randomized European study. N Engl J Med 360: 1320-1328, 2009.

16. Rajasekaran AK, Anilkumar G and Christiansen JJ: Is prostate-specific membrane antigen a multifunctional protein? Am J Physiol Cell Physiol 288: C975-C981, 2005.

17. Ghosh A and Heston WD: Tumor target prostate specific membrane antigen (PSMA) and its regulation in prostate cancer. J Cell Biochem 91: 528-539, 2004.

18. Mohler JL, Kantoff PW, Armstrong AJ, Bahnson RR, Cohen M, D'Amico AV, Eastham JA, Enke CA, Farrington TA, Higano CS, et al; National comprehensive cancer network: Prostate cancer, version 1.2014. J Natl Compr Canc Netw 11: 1471-1479, 2013.

19. Auprich M, Bjartell A, Chun FK, de la Taille A, Freedland SJ, Haese A, Schalken J, Stenzl A, Tombal B and van der Poel H: Contemporary role of prostate cancer antigen 3 in the management of prostate cancer. Eur Urol 60: 1045-1054, 2011.

20. Zheng SL, Sun J, Wiklund F, Smith S, Stattin P, Li G, Adami HO, Hsu FC, Zhu Y, Bälter K, et al: Cumulative association of five genetic variants with prostate cancer. N Engl J Med 358: 910-919, 2008.

21. De Wever W, Coolen J and Verschakelen JA: Integrated PET/CT and cancer imaging. JBR-BTR 92: 13-19, 2009.

22. Del Vecchio S, Zannetti A, Fonti R, Iommelli F, Pizzuti LM, Lettieri A and Salvatore M: PET/CT in cancer research: From preclinical to clinical applications. Contrast Media Mol Imaging 5: 190-200, 2010.

23. Patel CN, Goldstone AR, Chowdhury FU and Scarsbrook AF: FDG PET/CT in oncology: 'Raising the bar'. Clin Radio 165: 522-535, 2010

24. Picchio M, Briganti A, Fanti S, Heidenreich A, Krause BJ, Messa C, Montorsi F, Reske SN and Thalmann GN: The role of choline positron emission tomography/computed tomography in the management of patients with prostate-specific antigen progression after radical treatment of prostate cancer. Eur Urol 59: 51-60, 2011 